\title{
Stadtbücherei Frankfurt am Main wurde Bibliothek des Jahres 2018
}

\section{Oberbürgermeister Peter Feldmann lud zur Feierstunde}

http://doi.org/10.1515/bd-2019-0005

Am 24. Oktober 2018, am bundesweiten „Tag der Bibliotheken“, erhielt die Stadtbücherei Frankfurt am Main den nationalen Bibliothekspreis „Bibliothek des Jahres“. Ausgezeichnet wurde die Stadtbücherei für ihre vorbildliche Schulbibliotheksarbeit. Mit ihrer Schulbibliothekarischen Arbeitsstelle wurde eine bundesweit einmalige Servicestelle einer Stadtbücherei prämiert, deren Konzept für Kommunen im In- und Ausland Modellcharakter hat. Der Preis ist mit 20.000 Euro dotiert und wird vom Deutschen Bibliothekverband e. V. und der Deutsche Telekom Stiftung vergeben.

Oberbürgermeister Peter Feldmann war Gastgeber der Feierstunde im Kaisersaal im Frankfurter Römer. Es sprachen außerdem Sylvia Weber, Dezernentin für Integration und Bildung, und Barbara Lison, Bundesvorsitzende des Deutschen Bibliotheksverbandes e. V. Der Autor Feridun Zaimoglu, ein bekennender Bibliotheksfan, bestritt den literarischen Part mit einer exklusiven Lesung. Die Preisübergabe an die Leiterin der Stadtbücherei Frankfurt am Main, Dr. Sabine Homilius, erfolgte durch Dr. Frank Mentrup, Oberbürgermeister der Stadt Karlsruhe und Präsident des Deutschen Bibliotheksverbandes e. V. und Prof. Dr. Wolfgang Schuster, Vorsitzender Deutsche Telekom Stiftung.

Weitere Informationen finden Sie hier: https://www.bibliotheksverband.de/ $\mathrm{dbv/presse/presse-details/archive/2018/june/article/medienbildung-und-lese-}$ kompetenz-durch-schulbibliotheken-die-stadtbuecherei-frankfurt-am-main-ist. html?tx_ttnews\%5Bday\%5D=11\&cHash=a704635ef629938c9ff9701fb0dab85d.

\section{Kontakt: Deutscher Bibliotheksverband e.V.}

Maiken Hagemeister, Pressesprecherin und Leitung Kommunikation, Tel.: 0 30/644 989925

E-Mail: hagemeister@bibliotheksverband.de, http://www.bibliotheksverband.de, http://www.bibliotheksportal.de 